ORIGINAL ARTICLE

\title{
Knowledge and attitude of women towards alcohol use and related problems in the Eastern part of Nepal
}

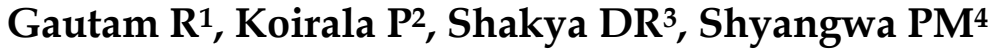

1. Associate Professor, Department of Psychiatry, BPKIHS, Dharan, Nepal 2. Senior Resident, Department of Psychiatry, BPKIHS, Dharan, Nepal 3. Additional Professor, Department of Psychiatry, BPKIHS, Dharan, Nepal 4. Professor, Department of Psychiatry, BPKIHS, Dharan, Nepal.

E-mail *Corresponding author: rinkugautam@hotmail.com

\begin{abstract}
Introduction: Exploring the levels of knowledge and attitude of women towards alcohol use and related problems will enable a more efficient process of awareness creation and it will allow the program to be tailored more appropriately to the needs of the community. Females with alcohol problems are severely impaired; have adverse consequences and more alcohol related physical, psychological and social harm.

Objective: To explore the knowledge and attitude of women towards alcohol use and related problems.

Method: A hospital based cross sectional descriptive study. The selected participants were consecutive female patients with alcohol related problem who came under the health care service of psychiatry, consultation liaison and other departments of BPKIHS, Dharan scoring two or more scores in T-ACE questionnaire. The patients in abstinence for two or less than two months, more than 16 years of age and who gave informed written consent were included in the study. A semi- structured proforma was designed to collect the data.. Mean, Standard deviation and percentage was used for analysis.

Results: A total of 49 female patients participated in the study after giving their written informed consent. The overall knowledge of the respondents regarding the alcohol use was inadequate as only 8 subjects (16.3\%) had adequate knowledge (scored $\geq 60 \%$ ). The mean score was $21.04 \pm 8.48(43.8 \pm 17.6 \%)$. Positive attitude was shown by $64.46 \pm 21.93 \%$. Negative attitude was shown by $25.76 \pm 16.76 \%$ and the rest $9.8 \%$ gave did not know response.
\end{abstract}

Conclusion: The knowledge among the respondents was inadequate but the attitude towards alcohol use was positive. This indicates need for targeting an effective intervention.

Keywords: Knowledge \& Attitude, Alcohol, Women, Nepal

\section{INTRODUCTION}

Alcohol is the oldest, most widely used and easily prepared psychoactive substance. It has been used in all societies throughout recorded history and has always had a place in the lifestyles and formal rituals around the world including Nepal. It has been used by people around the world in the standard diet, for hygienic/medical reasons; relaxant and euphoric effects; recreational purposes; artistic 
inspiration, as aphrodisiacs, and for other reasons. There are also recorded attempts of controlling its use by authorities, though societies have always found it difficult to understand or restrain its use.1,2

The three main mechanisms of harm from alcohol are intoxication, dependence and toxicity. It can exacerbate pre-existing mental and physical disorders; it can adversely interact with other prescribed and illicit drugs in the body; acts as an intoxicating substance, is associated with a wide range of intentional and unintentional injury; and can produce a dependence syndrome, with an abuse liability. ${ }^{3}$ Even with the evidence that alcohol use has a devastating effect on women; it is unfortunate that societal attitudes continue to stigmatize women with alcohol drinking habit. Until this perception towards alcohol use in women persists, women will continue to suffer and fail to present themselves for treatment. Societal attitudes towards women and alcohol are barriers to the detection and treatment of female alcohol related problems. Fear of stigmatization may lead women to deny that they are suffering from a medical condition; they hide their drinking and drink alone. ${ }^{4}$

Knowledge refers to the understanding of the alcohol use and its effects and attitude refers to their feelings towards alcohol use, and any preconceived ideas that they may have towards it. Exploring the levels of knowledge and attitude will enable a more efficient process of awareness creation and it will allow the program to be tailored more appropriately to the needs of the community. ${ }^{5}$ Hence, this study is undertaken to explore the knowledge and attitude towards alcohol use, as females with alcohol problems are severely impaired, have many adverse consequences and have more alcohol related physical, psychological and social harm.

\section{MATERIAL AND METHOD}

This was a hospital based cross sectional descriptive study. The selected participants were consecutive female patients with alcohol related problem who came under the health care service of psychiatry, consultation liaison and other departments of BPKIHS, Dharan scoring two or more scores in T-ACE questionnaire, those who were in abstinence for two or less than two months, those who gave informed written consent to participate in the study and were more than 16 yrs. Patient with multiple substance dependence, or who were severely ill and could not give informed consent and did not have reliable care taker to give consent were excluded.

A self-designed knowledge and attitude questionnaire was applied. All the questionnaires were translated to Nepali and back translated to English by standard procedure. The study duration was from 2009 2010. The ethical approval for the study was obtained from the Institute's Ethical Board. The data was analysed using SPSS version 14.0.

\section{RESULT}

Forty nine female patients were included in the study. The knowledge was assessed by reviewing the questionnaires. There were 48 questions regarding the knowledge about the alcohol use. Scoring was done, 1 score for each correct response only and 0 score was given to the incorrect as well the 'did not know' response. The score of $\geq 60 \%$ ie $\geq 29$ score out of 48 questions was considered to be adequate knowledge. Total 0 score means there were not even a single correct response. Eight subjects $(16.3 \%)$ had adequate knowledge (scored $\geq$ $60 \%$ ). The mean score was $21.04 \pm 8.48$ $(43.8 \pm 17.6 \%)$ when calculating the correct response and not taking into account the incorrect response and didn't know response. The knowledge about the advantages of alcohol was better than overall knowledge, mean score being $46.15 \pm 22.86 \%$. Fifteen cases $(30.61 \%)$ had adequate knowledge.

Positive attitude was shown by $64.46 \pm 21.93 \%$. Negative attitude by $25.76 \pm 16.76 \%$ and the rest $9.78 \%$ (range 0 to $40.8 \%$ ) gave didn't know. response.

Details of the result are shown in Table 1 and Table 2.

Table 1: Distribution of knowledge regarding alcohol use among the cases 


\begin{tabular}{|c|c|c|c|c|}
\hline S.No. & Questions & Yes $n(\%)$ & No $n(\%)$ & Don't know n(\%) \\
\hline 1 & Alcohol drinking is good for health & $7(14.3)$ & $38(77.6)$ & $4(8.2)$ \\
\hline 2 & The advantages of alcohol drinking & & & \\
\hline 2.1 & Pain abdomen is relieved & $26(53.1)$ & $19(38.8)$ & $4(8.2)$ \\
\hline 2.2 & Increases the digestive power & $19(38.8)$ & $22(44.9)$ & $8(16.3)$ \\
\hline 2.3 & Kills the worms of the intestine & $9(18.4)$ & $26(53.1)$ & $14(28.6)$ \\
\hline 2.4 & Increases the energy & $29(59.2)$ & $19(38.8)$ & $1(2.0)$ \\
\hline 2.5 & Makes you feel warm in winter & $42(85.7)$ & $1(2.0)$ & $6(12.2)$ \\
\hline 2.6 & Decreases the restlessness & $31(63.3)$ & $14(28.6)$ & $4(8.2)$ \\
\hline 2.7 & Easy to work & $27(55.1)$ & $19(38.8)$ & $3(6.1)$ \\
\hline 2.8 & Increases the social status & $5(10.2)$ & $37(75.5)$ & $7(14.3)$ \\
\hline 2.9 & Increases the intelligence & $4(6.1)$ & 39 (79.6) & $6(12.2)$ \\
\hline 2.10 & Invites arguments/quarrels/fights & $33(67.3)$ & $16(32.7)$ & 0 \\
\hline 2.11 & Resolves the arguments/quarrel/fights & $15(30.6)$ & $32(65.3)$ & $2(4.1)$ \\
\hline 2.12 & Increases friendship & 37 (75.5) & $11(22.4)$ & $1(2.0)$ \\
\hline 2.13 & Cures Mental Illnesses & $2(4.1)$ & $23(46.9)$ & $24(49)$ \\
\hline 3 & Alcohol drinking habit is & & & \\
\hline 3.1 & Harmful for health & $36(73.5)$ & $8(16.3)$ & $5(10.2)$ \\
\hline 3.2 & A disease condition & $22(44.9)$ & $13(26.5)$ & $14(28.6)$ \\
\hline 3.3 & A hereditary condition & $18(36.7)$ & $17(34.7)$ & $14(28.6)$ \\
\hline 3.4 & Controlled after getting married & $5(10.2)$ & $30(61.2)$ & $14(28.6)$ \\
\hline 4 & Alcohol drinking causes adverse changes in brain & $10(20.4)$ & $11(22.4)$ & $28(57.1)$ \\
\hline 5 & Alcohol drinking is more harmful for female than male. & $28(57.1)$ & $7(14.3)$ & $14(28.6)$ \\
\hline 6 & The pregnant woman should drink & $13(26.5)$ & $27(55.1)$ & $9(18.4)$ \\
\hline 7 & Drinking during pregnancy will have adverse effect for baby & $20(40.8)$ & $12(24.5)$ & $17(34.7)$ \\
\hline 8 & The lactating mother should drink & $33(67.3)$ & 9 (18.4) & $7(14.3)$ \\
\hline 9 & Treatment options are available for quitting alcohol drinking & $16(32.7)$ & $5(10.2)$ & $28(57.1)$ \\
\hline 10 & The advantages of drinking during pregnancy are & & & \\
\hline 10.1 & Increases the appetite of the mother & $26(53.1)$ & $12(24.5)$ & $11(22.4)$ \\
\hline 10.2 & Makes the mother active & $25(51)$ & $17(34.7)$ & $7(14.3)$ \\
\hline 10.3 & Increases the energy of the mother & $28(57.1)$ & $13(26.5)$ & $8(16.3)$ \\
\hline 10.4 & For overall development of the baby & $3(6.1)$ & $24(49)$ & $22(44.9)$ \\
\hline 10.5 & The mental growth of the baby is enhanced & $2(4.1)$ & $24(49)$ & $23(46.9)$ \\
\hline 10.6 & Increases the weight of the baby & $18(36.7)$ & $19(38.8)$ & $12(24.5)$ \\
\hline 11 & The advantages of drinking by lactating mother are & & & \\
\hline 11.1 & Increases the milk production & $36(73.5)$ & $6(12.2)$ & $7(14.3)$ \\
\hline 11.2 & For the health of mother & $35(71.4)$ & 7 (14.3) & $7(14.3)$ \\
\hline 11.3 & Increases the mother's energy & $34(69.4)$ & $9(18.4)$ & $6(12.2)$ \\
\hline 11.4 & Cleans the blood of mother & $29(59.2)$ & $8(16.3)$ & $12(24.5)$ \\
\hline 12 & Alcohol drinking habit should be treated & $22(44.9)$ & $11(22.4)$ & $16(32.7)$ \\
\hline 13 & Alcohol drinking habit can be cured by oneself & $36(73.5)$ & $11(22.4)$ & $2(4.1)$ \\
\hline 14 & After the person stops drinking, she may again start drinking & $16(32.7)$ & $21(42.9)$ & $12(24.5)$ \\
\hline 15 & Treatment options for alcohol drinking habit are & & & \\
\hline 15.1 & Worshipping and praying to god & $13(26.5)$ & $28(57.1)$ & $8(16.3)$ \\
\hline 15.2 & Yoga, meditation & $7(14.3)$ & $34(69.4)$ & $8(16.3)$ \\
\hline 15.3 & Ayurvedic treatment & $6(12.2)$ & $33(67.3)$ & $10(20.4)$ \\
\hline 15.4 & Homeopathic treatment & $6(12.2)$ & $32(65.3)$ & $11(22.4)$ \\
\hline 15.5 & Herbal medicines & $5(10.2)$ & $32(65.3)$ & $12(24.5)$ \\
\hline 15.6 & Traditional faith healers - dhami, jhakri & $8(16.3)$ & $34(69.4)$ & $7(14.3)$ \\
\hline 15.7 & General medical practioners & $14(28.6)$ & $13(26.5)$ & $22(44.9)$ \\
\hline 15.8 & Psychiatrists & $20(40.8)$ & $6(12.2)$ & $23(46.9)$ \\
\hline 15.9 & Mental Hospital & $22(44.9)$ & 9 (18.4) & $18(36.7)$ \\
\hline 15.10 & Psychologists & $5(10.2)$ & $15(30.6)$ & $29(59.2)$ \\
\hline 15.11 & Rehabilitation centres & $26(53.1)$ & $5(10.2)$ & $18(36.7)$ \\
\hline
\end{tabular}


Table 2: Distribution of Attitude regarding alcohol use among the cases

\begin{tabular}{|c|c|c|c|c|}
\hline S.No. & Questions & $\begin{array}{c}\text { Yes } \\
\text { n (\%) }\end{array}$ & $\begin{array}{c}\text { No } \\
\text { n (\%) }\end{array}$ & $\begin{array}{c}\text { Don't know } \\
\text { n }(\%)\end{array}$ \\
\hline 1 & Alcohol drinking is a & & & \\
\hline 1.1 & Habit & $39(79.6)$ & $10(20.4)$ & 0 \\
\hline 1.2 & Need & $10(20.4)$ & $39(79.6)$ & 0 \\
\hline 1.3 & Bad moral character & $12(24.5)$ & $31(63.3)$ & $6(12.2)$ \\
\hline 1.4 & Pleasure & $33(67.3)$ & $15(30.6)$ & $1(2.0)$ \\
\hline 1.5 & Part of rites and rituals & $38(77.6)$ & $11(22.4)$ & 0 \\
\hline 1.6 & Sanctioned by caste & $40(81.6)$ & $8(16.3)$ & $1(2.0)$ \\
\hline 1.7 & Tension reliever & $39(79.6)$ & $7(14.3)$ & $3(6.1)$ \\
\hline 1.8 & Decreases the tiredness & $41(83.7)$ & $6(12.2)$ & $2(4.1)$ \\
\hline 2 & The cause of alcohol drinking habit is /due to & & & \\
\hline 2.1 & Peer pressure & $36(73.5)$ & $12(24.5)$ & $1(2.0)$ \\
\hline 2.2 & For new thoughts & $6(12.2)$ & $34(69.4)$ & $9(18.4)$ \\
\hline 2.3 & Family rules & $38(77.6)$ & $11(22.4)$ & 0 \\
\hline 2.4 & Decrease tension & $44(89.8)$ & $3(6.1)$ & $2(4.1)$ \\
\hline 2.5 & To decrease fear & $25(51)$ & $21(42.9)$ & $3(6.1)$ \\
\hline 2.6 & Due to witchcraft & $36(73.5)$ & $6(12.2)$ & $7(14.3)$ \\
\hline 2.7 & Due to sin or other mistakes & $6(12.2)$ & $33(67.3)$ & $10(20.4)$ \\
\hline 3 & The female drinks to & & & \\
\hline 3.1 & Take care of family & $5(10.2)$ & $41(83.7)$ & $3(6.1)$ \\
\hline 3.2 & To maintain social status & $13(26.5)$ & $33(67.3)$ & $3(6.1)$ \\
\hline 3.3 & To increase energy & $31(63.3)$ & $17(34.7)$ & $1(2.0)$ \\
\hline 3.4 & To pass time & $23(46.9)$ & $25(51)$ & $1(2.0)$ \\
\hline 3.5 & To become active & $27(55.1)$ & $19(38.8)$ & $3(6.1)$ \\
\hline 4 & Alcohol drinking habit can be prevented by & & & \\
\hline 4.1 & Good company & $42(85.7)$ & $6(12.2)$ & $1(2.0)$ \\
\hline 4.2 & Good family environment & $42(85.7)$ & $5(10.2)$ & $2(4.1)$ \\
\hline 4.3 & Will power & $42(85.7)$ & $5(10.2)$ & $2(4.1)$ \\
\hline 4.4 & Banning alcohol production at home & $27(55.1)$ & $12(24.5)$ & $10(20.4)$ \\
\hline 4.5 & Restriction on alcohol production and sales & $23(46.9)$ & $13(26.5)$ & $13(26.5)$ \\
\hline 4.6 & Strict government rules and regulations & $17(34.7)$ & $7(14.3)$ & $25(51)$ \\
\hline 4.7 & Strict action on alcohol abusers & $16(32.7)$ & $13(26.5)$ & $20(40.8)$ \\
\hline
\end{tabular}

\section{DISCUSSION:}

The knowledge refers as to the understanding about alcohol use and its effects on female, and the attitude refers to their feelings towards alcohol use, as well as any preconceived ideas that they may have towards it. Understanding and knowing the levels of knowledge and attitude will enable a more efficient process of awareness creation and it will help the program to be tailored more appropriately to the needs of the community. The success of programs aiming at improving the life of people with alcohol use depends on the knowledge and attitude towards alcohol use. There have been a lot of studies attempted at finding out the knowledge and attitude regarding alcohol use.612

The knowledge about alcohol use during pregnancy was inadequate. Only 13 cases $(26.5 \%)$ had adequate knowledge. Seventeen cases $(34.7 \%)$ had scored 0. A study in Canada 
showed that there was a high level of knowledge that alcohol use during pregnancy is harmful to the child, and more the consumption the more the harmful and likely the effects, but there is confusion about the safety of small amount of alcohol. ${ }^{12}$

The knowledge about alcohol use during lactation was also inadequate. Only 6 cases $(12.24 \%)$ had adequate knowledge. Thirty six cases $(73.4 \%)$ had scored 0 . In a study in Australia by Roslyn et al., 9 the mothers were largely unaware of the side effects of alcohol on breastfeeding performance and development of the infant. The majority expressed the concern at lack of information available regarding safe alcohol consumption practice during lactation.

The knowledge about the treatment options was also inadequate, the mean score was $51.94 \pm 21.71 \%$; 20 cases $(40.81 \%)$ had adequate knowledge. In a study by Shakya DR et al,13 inadequate knowledge about treatment option was reported as a reason behind delayed treatment seeking. About $17 \%$ did not know about the treatment options.

The respondents regarded alcohol drinking as a habit $(79.6 \%)$, pleasure $(67.3 \%)$, part of rites and rituals $(77.6 \%)$, sanctioned by caste $(81.6 \%)$, tension reliever $(79.6 \%)$ and decreases the tiredness $(83.7 \%)$, bad moral character $(24.5 \%)$ and a need (20.4\%). Altogether, $76.5 \%$ had positive attitude, $18.2 \%$ had negative attitude and $5.3 \%$ responded as "did not know".

The respondents regarded the cause of alcohol drinking was due to peer pressure $(73.5 \%)$, for new thoughts $(12.2 \%)$, family rules $(77.6 \%)$, to decrease tension $(89.8 \%)$, to decrease fear $(51 \%)$, witchcraft $(73.5 \%)$, sin or other mistakes $(12.2 \%)$. Altogether, $54.8 \%$ had positive attitude, $34.4 \%$ had negative attitude and $10.8 \%$ responded as did not know.

The respondents regarded female drank to take care of family $(10.2 \%)$, to maintain social status $(26.5 \%)$, to increase energy $(63.3 \%)$ and to become active (55.1\%). Altogether, $63.2 \%$ had positive attitude, $32.3 \%$ had negative attitude and $4.5 \%$ responded as did not know.
The respondents regarded the following as the ways to prevent alcohol drinking habit good company $(85.7 \%)$, good family environment $(85.7 \%)$, strong will power $(85.7 \%)$, banning alcohol production at home $(55.1 \%)$, restriction on alcohol production and sales $(46.9 \%)$, strict government rules and regulations (34.7\%) and strict action on alcohol abusers (32.7\%). Altogether, $60.9 \%$ had positive attitude, $17.8 \%$ had negative attitude and $21.3 \%$ responded as did not know.

Overall, positive attitude was shown by $64.46 \pm 21.93 \%$. Negative attitude by $25.76 \pm 16.76 \%$ and the rest $9.8 \%$ gave did not know response. So, the attitude towards alcohol use was positive. This is consistent with finding of the study done by Binod $\mathrm{K}$ Deo et $\mathrm{al}^{6}$ carried out in a school, where the attitude towards the alcohol use and alcohol users was positive. In a study by Shakya DR, ${ }^{13}$ two third of the subjects didn't realize the alcohol use as a problem and $10 \%$ had negative attitudes towards the modern measures and preferred other alternative methods.

This positive attitude towards the alcohol use signifies the socially accepted status of the alcohol use, especially in this part. The reason for high positive attitude may be because the respondents were themselves the alcohol users.

There are limitations in the study as the sample size was small, and it is a hospital based s study. So, the sample might not represent the general population and the results may not be applicable to the community. The respondents female alcohol users themselves, so it may only represent the viewpoint of the female alcohol users but not the general population. There was a dearth of literature regarding the knowledge and attitude, so the findings of the present study could not be compared to other studies. Alcohol use is a sensitive issue, thus some information may have been distorted or concealed.

\section{CONCLUSION:}

The knowledge among the respondents was inadequate but the attitude towards alcohol use was positive. This indicates need for targeting 
intervention effective in the reproductive age group to prevent the dual hazards; to the mother of the physical, psychiatric and social harm due to alcohol and to the fetus from the fetal alcohol syndrome. The findings of this study may pave way to larger community based study.

\section{REFERENCES:}

1. David Semple et al. (2005) Oxford Handbook of Psychiatry. Oxford Medical Publications. p 504 .

2. Alcohol, Gender and Drinking Problems: Perspectives from Low and Middle Income Countries. WHO 2005.

3. WHO Expert Committee on Problems related to Alcohol Consumption, 2nd Report, WHO Technical Report Series 944.

4. Blume Laura N., Nielson Nancy H., Riggs Joseph A., et al. Alcoholism and alcohol abuse among women: report of the council on scientific affairs. Journal of women's health. 1998; 7 (7): 861-870.

5. Kaliyaperumal K. Guideline for conducting a Knowledge, Attitude and Practice Study AECS Illumination. 2004; IV (1):7-9.

6. Binod K. Deo, Pramod Shyangwa et al. Survey on KAP of alcohol and other substance use/abuse among the high school students in Dharan. Institution based study. 2003.

7. Christopher Smith, Laura L. Pendleton et al. People's knowledge of alcohol - a workplace survey. Health Education Journal. 1989; 48(1): 33-35.

8. C. Rowe, J.R. Kemm. Do people understand 'units of alcohol'? Health Education Journal. 1992; 51(2): 59-63.

9. Rosly C Giglia, Colin W Binns. Alcohol and breastfeeding: what do Australian mothers know? Asia Pac J Clin Nutr. 2007;16 (Suppl 1):473-477.

10. Peadon E, Payne J, Henley N, D'Antoine H, Bartu A, Bower C, Elliott E. Alcohol and Pregnancy: Women's Knowledge, Attitudes and Practice. Journal of Paediatrics \& Child Health. 2007; 43(A12): 7-8.

11. TK Logan, Robert Walker, Laura Nagle, Jimmie Lewis, A Donna Wiesenhahn. Rural and Small-Town Attitudes about Alcohol Use During Pregnancy: A Community and Provider Sample. The Journal of Rural Health; 19(4):497 - 505.

12. Awareness of the Effects of Alcohol Use During Pregnancy And Fetal Alcohol Syndrome Results of a National Survey.
2000. Environics Research Group Limited, Canada.

13. Shakya DR, 2005. MD thesis. Alcohol Dependence Syndrome. 